\title{
Chronic Kidney Disease between Obscure Etiologies and Serious Complications among Lebanese Patients
}

\author{
Ali Salami, ${ }^{1,}$ Fatima Karaki, ${ }^{2}$ and Wissam H. Joumaa ${ }^{1}$ \\ ${ }^{1}$ Environmental Physio-Toxicity Laboratory (PhyToxE), Faculty of Sciences, Lebanese University, Nabatieh, Lebanon \\ ${ }^{2}$ Department of Nutrition, Faculty of Sciences, Lebanese University, Beirut, Lebanon \\ "Corresponding author: Ali Salami, Environmental Physio-Toxicity Laboratory (PhyToxE), Faculty of Sciences, Lebanese University, Nabatieh, Lebanon. Tel: +961-7765980-Ext.136, \\ E-mail: salami.ali@hotmail.com
}

Received 2016 April 14; Revised 2016 June 14; Accepted 2016 August 21.

\begin{abstract}
Background: Chronic Kidney Disease (CKD) and Diabetic Nephropathy (DN) are currently a major public health threat.

Objectives: The objective of this paper is to define the leading causes of CKD and DN and their complications among Lebanese patients.

Patients and Methods: In this study, 380 hemodialysis patients were included, regardless of their socioeconomic status or nationality.

Results: In total, $89.5 \%$ of patients were over the age of 40 . The main cause of CKD was hypertension (55.3\%), followed by polycystic kidney disease and repeated urinary tract infections (34.2\%). The nutritional analysis of patients' dietary history showed that $52.6 \%$, $31.6 \%$, and $47.4 \%$ of patients exceeded their Recommended Dietary Allowance (RDA) of protein, caffeine, and sodium, respectively. In terms of the consequences of CKD, men were more prone to anemia and water retention than women. However, women were more affected by cardiovascular disease and malnutrition. Concerning age, anemia was more prevalent in younger patients than in older ones.

Conclusions: The high prevalence of behavioral and pathological factors and the resulting consequences of CKD suggest a major awareness of the Lebanese population of the risks of chronic kidney disease and the necessity of the prevention of CKD by following a healthy lifestyle and managing any existing diseases.
\end{abstract}

Keywords: Chronic Kidney Disease, Causes, Consequences

\section{Background}

Chronic kidney disease is a general term for heterogeneous disorders affecting kidney structure and function in blood filtration and hormone secretion. This disease is rare before the age of 45 , and its prevalence increases with age, especially after 65 (1-3). In France, it is linked in almost a quarter of reported cases with hypertension and in another quarter to diabetes (4). According to a 2003 study, ten years after the onset of diabetes, one-third of patients develop kidney failure, $6 \%$ of which are in advanced stages (5), but proper management of diabetes could alter these results (4).

Glomerulonephritis is due to frequent urinary tract infections, especially in women, and the rise of the germ in the kidneys $(4,6)$. It was the leading cause of kidney failure in the 1990s, although this is no longer a concern since it is now the leading cause in only $12 \%$ of patients (4). More than $6 \%$ of cases are related to an inherited genetic condition called polycystic kidney disease, characterized by numerous cysts in the kidneys $(4,7)$. Other risk factors that may cause chronic renal disease include obesity, hyperlipidemia, smoking, urinary tract obstruction (as in prostate hypertrophy and kidney stones), and autoimmune diseases, such as systemic lupus erythematous (6-15).

Recent studies have shown that the prevalence of CKD is influenced by many factors including sex $(11,16)$, sleep disorders (17), amount of water consumed per day (18-20), consumption of a high protein diet (21), and excessive consumption of sodium $(22,23)$. Obviously, the causes of CKD vary among populations and even within the same population, according to genetic and environmental factors. Kabir et al. (11) showed that glomerulonephritis was the main cause of CKD in Bangladesh (67.2\%), followed by diabetes (24\%) and hypertension (4.8\%). In another study in the Congo, Sumaili et al. (13) reported that the main causes of CKD were hypertension (26.6\%), diabetes (11.7\%), and obesity (14.9\%).

The major complications of CKD are cardiovascular events, sodium accumulation in the body, and the increased secretion of hypertensive hormones by the kidney, and it is often accompanied by an increase in blood pressure and other cardiovascular complications $(24,25)$. Calcium and phosphorus disorders are also common. One 
consequence of these anomalies is osteoporosis among adults (26). Kidney disease may affect erythropoietin (EPO) secretion, and thus the development of anemia may occur (27). Malnutrition is also widespread (4). Other signs, such as neurological disorders, may occur at very advanced stages of the disease (4).

Diabetic nephropathy is one of the most common complications of diabetes and is largely at the top of the leading causes of end-stage renal disease. Epidemiological evidence from many countries shows a significant increase in the number of dialysis patients with diabetes (28). Hyperglycemia, hypertension, smoking, and dyslipidemia are considered risk factors for CKD patients with diabetes (29). Chakkarwar et al. (30) showed that chronic smoking plays an important role in the progression of diabetic nephropathy. Tofovic et al. (31) showed that excessive consumption of caffeine worsens the state of kidney failure in obese and diabetic rats. Ritz et al. (32) showed that anemia is more common in diabetics than in non-diabetics, regardless of their glomerular filtration rate.

\section{Objectives}

The purpose of this study is to describe the prevalence, causes, and consequences of CKD and diabetic nephropathy on haemodialysis patients in Lebanon.

\section{Patients and Methods}

\subsection{Participants}

This cross-sectional survey was conducted between June 2015 and January 2016. A multi-stage stratified cluster sampling procedure was employed to select a representative sample of the primary care population in Lebanon. Two hospitals in the city of Nabatieh (south of Lebanon) and four in Beirut city were randomly chosen in proportion to the population size of each city. In this study, all the hemodialysis patients found in these hospitals (380 patients over the age of 18) are included, regardless of their socioeconomic status or their nationality. After obtaining permission to conduct the study in the hospital, we first obtained a list of the patients' names and the calendar of dialysis sessions for each patient. Second, data was collected from patients during their dialysis sessions. To ensure good communication, the selected patients had to have good cognitive, physical, and psychic abilities. Patients who did not meet the inclusion criteria, or those who were suffering from acute diseases, were excluded from the study.

\subsection{Measurements}

A questionnaire composed of four main parts was developed using previous questionnaire-based research (33, 34). The first part focused on the demographic and general characteristics of participants, such as age, gender, education level, family history with CKD, and past body mass index. The second part included questions on behavioral history of patients and their quality of life (e.g., smoking and sleep quality) with a food frequency questionnaire (water, protein, salt, and caffeine). The third part aimed to determine the patients' medical history in order to verify if they were affected by diabetes, diabetic nephropathy, hypertension, polycystic kidney disease, glomerulonephritis, lupus erythematosus, kidney stones, and repeated urinary infections. The last part focused on the consequences of the CKD on patients' health, such as the development of anemia, cardiovascular disease, edema, osteoporosis, hypertension, and malnutrition. The questions were designed to be true/false or single-word answers to eliminate the need for patient explanations.

\subsection{Statistical Analysis}

Statistical analyses were conducted using SPSS software (version 20.0). The level of significance was set at $\mathrm{P}<$ 0.05 for all statistical analyses. Descriptive analyses were based on frequencies and percentages. The association between gender and each risk factor was assessed by bivariate analyses: the chi-square test was used to study the relationship with qualitative variables and t-student with continuous quantitative variables. The nutritional analysis of patients' dietary history was analyzed by a dietitian (one of the authors: F. Karaki). The odd ratio measured the associations of CKD consequences with male and female gender from one side and various age groups from the other side.

\section{Results}

This study concerns patients at the last stage of chronic kidney disease who regularly undergo hemodialysis sessions.

\subsection{Characteristics and Behavioral History Before CKD}

Men made up $57.9 \%$ of the patients, and $42.1 \%$ were women. Among 380 patients, 340 patients (representing $89.5 \%$ ) were over the age of 40 , while the others were younger. The study of the level of education showed that $52.6 \%$ of the patients had a low level (e.g., illiterate or did not proceed beyond primary education), $42.1 \%$ had a medium level (secondary education), and 5.3\% had a high level of education (university level). Although CKD can be transmitted hereditarily, our results showed that only 
28.9\% of patients had at least one family member who suffered from CKD. More than half of the patients had a BMI greater than $25 \mathrm{~kg} / \mathrm{m}^{2}$ (21.1\% and $34.2 \%$ were overweight or obese, respectively). As for smoking, 57.9\% of patients were smokers of cigarettes or Shisha, or had been smokers. Among 380 patients, 220 patients (representing 57.9\%) reported that they slept between six and eight hours a day, 90 subjects (representing 23.7\%) slept more than eight hours, and 70 subjects (representing 18.4\%) slept less than six hours. Concerning water consumption, $47.4 \%$, 39.5\%, and $13.2 \%$ of the patients reported that they drank less than two liters per day, more than three liters, or between two and three liters, respectively. Table 1 shows the repartition of these results according to gender.

\subsection{Medical History Before CKD}

Chronic renal failure is a disease affected by genetic, behavioral, and pathological factors. The major pathological cause of CKD was hypertension (55.3\% of patients), followed by polycystic kidney disease and repeated urinary tract infections (34.2\% of patients), urinary tract obstruction by kidney stones (26.3\%), diabetic nephropathy (18.4\%), glomerulonephritis (13.2\%), and lupus erythematosus (2.6\%). Figure 1 shows the repartition of these results by gender.

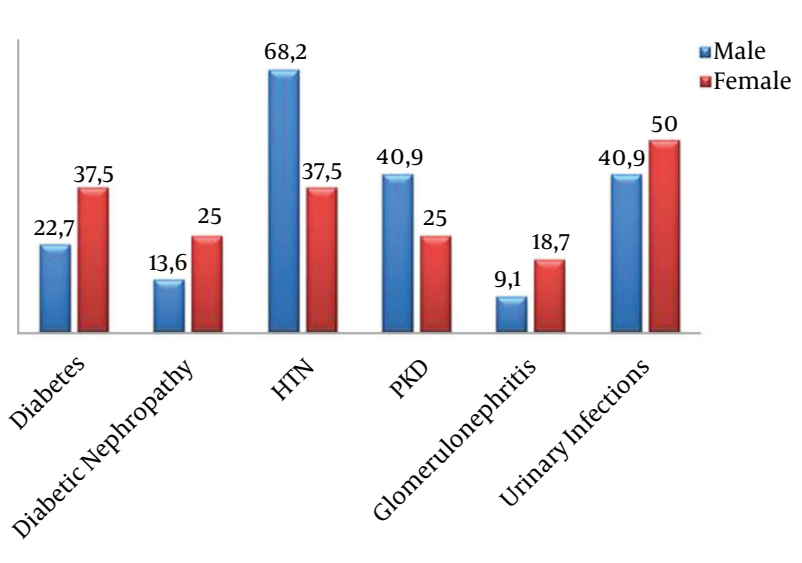

Figure 1. Medical History Before Renal Failure (January 2016)

\subsection{Food History Before CKD}

A balanced diet is essential to maintain kidney function. The study of the food history of the 380 patients with end-stage kidney disease showed that $52.6 \%$ of the patients consumed more than $56 \mathrm{~g}$ of protein per day, 31.6\% of the patients exceeded the recommended daily intake of caffeine ( $400 \mathrm{mg} /$ day), and $47.4 \%$ of patients consumed more than $2300 \mathrm{mg}$ of sodium per day (Table 2 ).

\subsection{CKD Consequences}

High blood pressure, cardiovascular disease, anemia, osteoporosis, malnutrition, and water retention (edema formation) are widespread consequences of chronic kidney disease. All of the 380 patients had permanent hypertension controlled by the regular hemodialysis sessions. A total of $55 \%$ of the patients suffered from anemia, $21 \%$ suffered from malnutrition, water retention, and edema formation, $18.4 \%$ had cardiovascular diseases, such as arteriosclerosis and myocardial damage, and 15.7\% suffered from osteoporosis.

The repartition of results regarding gender represented in Table 3 shows that among hemodialysis patients, men are more prone to anemia, water retention, and osteoporosis than women $(\beta=0.231, \mathrm{P}=0.042 ; \beta=0.347, \mathrm{P}$ $=0.199$; and $\beta=0.684, \mathrm{P}=0.671$, respectively). However, women are more affected by cardiovascular disease and malnutrition $(\beta=2.059, \mathrm{P}=0.428$ and $\beta=1.275, \mathrm{P}=0.767$, respectively).

Concerning age, anemia is more prevalent in younger patients (e.g., under 40 years) than in older ones ( $\beta=1.267$, $\mathrm{P}=0.823)$, whereas cardiovascular diseases, water retention, osteoporosis, and malnutrition are most prevalent in people over the age of 40 years $(\beta=0.044, \mathrm{P}=0.014 ; \beta=$ $0.778, \mathrm{P}=0.838 ; \beta=0.032, \mathrm{P}=0.008 ; \beta=0.057, \mathrm{P}=0.023$, respectively).

\subsection{Diabetic Nephropathy}

Among the 380 patients, 110 subjects had diabetes (representing $28.9 \%$ ), of which 70 had diabetic nephropathy (suffering from diabetic retinopathy, representing 18.4\% of hemodialysis patients). Diabetic nephropathy is one of the most common complications of diabetes and the top cause of end-stage renal disease. The results of this study show that patients with diabetic nephropathy adopted a diet rich in protein (71.4\%) but less rich in caffeine (42.9\%) and sodium (28.6\%) than other patients' diets. On the other hand, anemia (57.1\%) and cardiovascular diseases (28.6\%), such as arteriosclerosis and cardiac muscle atrophy, are more prevalent among patients with diabetic nephropathy than other patients. In contrast, the prevalence of water retention (14.3\%), osteoporosis (14.3\%), and malnutrition ( $0 \%)$ is lower among them (Table 4$)$.

\section{Discussion}

A silent and alarming epidemic is growing that will affect millions of people around the world. Like high blood pressure or diabetes, end-stage renal disease develops without warning signs. Several studies on the epidemiology and the prevalence of CKD and diabetic nephropathy 
Table 1. Characteristics and Behavioral History Before Renal Failure (January 2016) ${ }^{\mathrm{a}}$

\begin{tabular}{|c|c|c|c|c|}
\hline & Male $(\mathbf{n}=\mathbf{2 2 0})$ & Female $(n=160)$ & PValue & Total $(\mathbf{n}=\mathbf{3 8 0})$ \\
\hline Age & & & 0.001 & \\
\hline$<40$ & $20(9.1)$ & $20(12.5)$ & & $40(10.5)$ \\
\hline$\geq 40$ & $200(90.9)$ & $140(87.5)$ & & $340(89.5)$ \\
\hline Education level & & & 0.191 & \\
\hline Low & $100(45.5)$ & $100(62.5)$ & & $200(52.6)$ \\
\hline Medium & $100(45.5)$ & $60(37.5)$ & & $160(42.1)$ \\
\hline High & $20(9.1)$ & 0 & & $20(5.3)$ \\
\hline Family history of renal failure & $60(27.3)$ & $50(31.3)$ & 0.796 & $110(28.9)$ \\
\hline CKD duration in months (95\% CI) & $21.3-53.8$ & $11.1-25$ & 0.049 & $19.4-39.4$ \\
\hline Height in $\mathrm{cm}(95 \% \mathrm{CI})$ & $161.7-176.2$ & $155.6-164.4$ & 0.053 & $160.5-169.8$ \\
\hline Weight in $\mathrm{kg}(95 \% \mathrm{CI})$ & $72-90.9$ & $62.7-78.3$ & 0.085 & $70.5-83.2$ \\
\hline BMI & & & 0.862 & \\
\hline Underweight & $20(9.1)$ & 0 & & $20(5.3)$ \\
\hline Normal & $80(36.4)$ & $70(43.7)$ & & $150(39.5)$ \\
\hline Overweight & $40(18.2)$ & $40(25)$ & & $80(21.1)$ \\
\hline Obese & $80(36.4)$ & $50(31.3)$ & & $130(34.2)$ \\
\hline Smoking status & $150(68.2)$ & $70(43.7)$ & 0.139 & $220(57.9)$ \\
\hline Sleep duration (hours) & & & 0.363 & \\
\hline$<6$ & $30(13.6)$ & $40(25)$ & & $70(18.4)$ \\
\hline $6-8$ & $130(59.1)$ & $90(56.3)$ & & $220(57.9)$ \\
\hline$>8$ & $60(27.3)$ & $30(18.7)$ & & $90(23.7)$ \\
\hline Water intake (liters per day) & & & 0.665 & \\
\hline$<2$ & $110(50)$ & $70(43.8)$ & & $180(47.4)$ \\
\hline $2-3$ & $30(13.6)$ & $20(12.5)$ & & $50(13.2)$ \\
\hline$>3$ & $80(36.4)$ & $70(42.8)$ & & $150(39.5)$ \\
\hline
\end{tabular}

${ }^{\mathrm{a}}$ Values are expressed as No. (\%).

Table 2. Dietary Analysis for Hemodialysis Patients (January 2016)

\begin{tabular}{lccc}
\hline & $\begin{array}{c}\text { Recommended Dietary } \\
\text { Allowance (RDA) per day }\end{array}$ & $\begin{array}{c}\text { Percentage of Patients Below RDA, } \\
\%\end{array}$ & $\begin{array}{c}\text { Percentage of Patients Above RDA, Palue } \\
\%\end{array}$ \\
\hline Protein consumption per day & $0.8 \mathrm{~g} / \mathrm{kg}=56 \mathrm{~g} / \mathrm{d}$ & 47.4 & 52.6 \\
Caffeine consumption per day & $400 \mathrm{mg} / \mathrm{d}$ & 68.4 & 31.6 \\
\hline Sodium consumption per day & $2300 \mathrm{mg} / \mathrm{d}$ & 52.6 & 47.4 \\
\hline
\end{tabular}

were made in different countries $(11,13,28,29,32,35)$. However, data about the Middle East are rarely available. In this article, we studied for the first time the prevalence, causes, and consequences of CKD and DN in hemodialysis patients in Lebanon.

In accordance with several studies already carried out $(1,2,10,18,36)$, our study shows that advanced age, low ed- ucation levels, a BMI over $25 \mathrm{~kg} / \mathrm{cm}^{2}$, and smoking increase the prevalence of CKD. Contrary to what has been shown by Xue et al. (14), we noticed that men are more affected by CKD than women. This may be related to the protective effect of female hormones against renal aging (2). A study published in 2005 showed that CKD can be transmitted hereditarily, and a genetic abnormality can cause hy- 
Table 3. CKD Consequences (January 2016)

\begin{tabular}{|c|c|c|c|c|}
\hline & \multicolumn{2}{|c|}{ Sex } & \multicolumn{2}{|c|}{ Age Groups } \\
\hline & $\operatorname{Male}(\mathbf{n}=\mathbf{2 2 0})$ & Female $(n=160)$ & $\geq 40(n=340)$ & $<\mathbf{4 0}(\mathrm{n}=\mathbf{4 0})$ \\
\hline \multicolumn{5}{|l|}{ Anemia } \\
\hline No. (\%) & $90(40.1)$ & $120(75)$ & $190(55.9)$ & $20(50)$ \\
\hline Odd ratio $(95 \% \mathrm{CI})$ & 1.000 & $0.231(0.056,0.950)$ & 1.000 & $1.267(0.159,10.074)$ \\
\hline Pvalue & \multicolumn{2}{|c|}{0.042} & \multicolumn{2}{|c|}{0.823} \\
\hline \multicolumn{5}{|c|}{ Cardiovascular disease (myocardial disease or stroke) } \\
\hline No. $(\%)$ & $50(22.7)$ & $20(12.5)$ & $40(11.8)$ & $30(75)$ \\
\hline Odd ratio $(95 \% \mathrm{CI})$ & 1.000 & $2.059(0.345,12.281)$ & 1.000 & $0.044(0.004,0.537)$ \\
\hline Pvalue & \multicolumn{2}{|c|}{0.428} & \multicolumn{2}{|c|}{0.014} \\
\hline \multicolumn{5}{|c|}{ Edema (in lower limbs or lungs) } \\
\hline No. $(\%)$ & $30(13.6)$ & $50(31.3)$ & $70(20.6)$ & $10(25)$ \\
\hline Odd ratio (95\% CI) & 1.000 & $0.347(0.069,1.742)$ & 1.000 & $0.778(0.070,8.669)$ \\
\hline Pvalue & \multicolumn{2}{|c|}{0.199} & \multicolumn{2}{|c|}{0.838} \\
\hline \multicolumn{5}{|l|}{ Osteoporosis } \\
\hline No. $(\%)$ & $30(13.6)$ & $30(18.8)$ & $30(8.8)$ & $30(75)$ \\
\hline Odd ratio $(95 \% \mathrm{CI})$ & 1.000 & $0.684(0.119,3.933)$ & 1.000 & $0.032(0.003,0.415)$ \\
\hline Pvalue & \multicolumn{2}{|c|}{0.671} & \multicolumn{2}{|c|}{0.008} \\
\hline \multicolumn{5}{|l|}{ Malnutrition } \\
\hline No. (\%) & $50(22.7)$ & $30(18.8)$ & $50(14.7)$ & $30(75)$ \\
\hline Odd ratio $(95 \% \mathrm{CI})$ & 1.000 & $1.275(0.256,6.333)$ & 1.000 & $0.057(0.005,0.669)$ \\
\hline Pvalue & \multicolumn{2}{|c|}{0.767} & \multicolumn{2}{|c|}{0.023} \\
\hline
\end{tabular}

Table 4. Comparison Between Patients With Diabetic Nephropathy and Other Hemodialysis Patients, According to the Dietary History and the Consequences of CKD (January 2016)

\begin{tabular}{|c|c|c|c|c|}
\hline \multirow{2}{*}{$\begin{array}{l}\text { CKD Consequences } \\
\text { Anemia }\end{array}$} & \multicolumn{2}{|c|}{ CKD Cases not Caused by Diabetes, \% } & \multicolumn{2}{|c|}{ Diabetic Nephropathy Cases, \% } \\
\hline & \multicolumn{2}{|c|}{54.8} & \multicolumn{2}{|c|}{57.1} \\
\hline Cardiovascular disease & \multicolumn{2}{|c|}{16.1} & \multicolumn{2}{|c|}{28.6} \\
\hline Edema & \multicolumn{2}{|c|}{22.6} & \multicolumn{2}{|c|}{14.3} \\
\hline Osteoporosis & \multicolumn{2}{|c|}{16.1} & \multicolumn{2}{|c|}{14.3} \\
\hline Malnutrition & \% Below RDA & \% Above RDA & \% Below RDA & \% Above RDA \\
\hline \multicolumn{5}{|l|}{ Dietary analysis } \\
\hline Protein consumption per day & 51.6 & 48.4 & 28.6 & 71.4 \\
\hline Caffeine consumption per day & 71 & 29 & 57.1 & 42.9 \\
\hline Sodium consumption per day & 48.4 & 51.6 & 71.4 & 28.6 \\
\hline
\end{tabular}

peruricemia, which can gradually damage renal function (37). However, in this study, more than a quarter of the patients had at least one family member with CKD. Salifu et al. showed that sleep disorders are associated with a high prevalence of CKD (17). However, our results do not validate this hypothesis, since $60 \%$ of hemodialysis patients reported that they slept between six and eight hours per day. The influence of the consumption of water was also 
studied. Our results were consistent with previous studies that show that low water consumption is a risk factor for $\operatorname{CKD}(19,20)$.

In addition, other studies show that the most prevalent CKD risk factor is hypertension in South Africa and Congo (18, 38), glomerulonephritis in Bangladesh (11), and hyperlipidemia in China (14). In the current study, all of the 380 patients had permanent hypertension controlled by the regular hemodialysis sessions. In total, $55 \%$ of the patients suffered from anemia, 21\% suffered from malnutrition, water retention, and edema formation, $18.4 \%$ had cardiovascular diseases, such as arteriosclerosis and myocardial damage, and 15.7\% suffered from osteoporosis.

Regarding the relationship between sex and pathologies causing CKD, it was found that the prevalence of $\mathrm{DN}$, glomerulonephritis, and urinary infections is higher in women than in men, yet hypertension and polycystic kidney disease are more prevalent in men. This is consistent with what has been shown in other studies $(16,39-41)$.

The analysis of the dietary history of hemodialysis patients shows no relationship between excessive intake of sodium and protein and the occurrence of CKD. The results show no decisive effect on the impact of proteins on glomerular function, as Fatehi-Hassanabad and Chan showed (21). These results contradict earlier studies indicating a positive or a negative effect of sodium on renal function $(22,23)$. The effect of caffeine on renal function in humans has not been studied. However, this study was able to show a significant relationship between caffeine intake and the occurrence of CKD.

The consequences of CKD depend on the gender and the age of patients. First, all hemodialysis patients suffer from hypertension caused by the accumulation of water in the body and the inability of the kidneys to excrete urine. Although anemia is usually more common in women, because of blood loss during menstruation, the results showed that men undergoing hemodialysis were more prone to anemia. This is probably due to the fact that most women in the study were menopausal as well as the men experiencing a loss of blood or iron deficiency due to a very restrictive diet (42). Also, water retention and the formation of edema are more common in men than in women. This is possibly related to the tendency of men to consume more salt and the fact that they are more susceptible to dehydration. In addition, men are more affected by osteoporosis related to CKD, probably because of their advanced age. Yet, women are more susceptible to cardiovascular disease, probably due to their sedentary lifestyle. Thus, malnutrition is more common in women, possibly because of the difference in the amount of lean mass in women. It is not surprising that the complications of CKD increase with age, especially cardiovascular disease, osteo- porosis, and malnutrition. In contrast, the prevalence of anemia is higher at a younger age ( $<40$ years) due to the activity of female hormones and the monthly blood loss in women.

The study of diabetic nephropathy showed that almost $30 \%$ of patients were diabetic, but only $18 \%$ had diabetic nephropathy. It has been found that patients with DN have a higher risk for anemia and cardiovascular disease than others, because of the additional effect of diabetes, but a lower risk of having edema of the osteoporosis and malnutrition, for poorly understood reasons. The dietary history of DN patients showed that their diet was richer in protein and caffeine than other patients. Therefore, this diet can contribute to the acceleration of the progression of DN, then the damage to the glomerular filtration rate caused by diabetes. This is not the case for sodium, since these patients consumed a smaller amount than others.

This study was carried out to determine the prevalence, causes, and consequences of chronic kidney disease and diabetic nephropathy in Lebanon. Older age, low education levels, overweight and obesity, smoking, and consumption of an inappropriate amount of water are all factors that affect renal function and accelerate the progression of chronic kidney disease. In Lebanon, high blood pressure is the leading cause of end-stage kidney disease, followed by polycystic kidney disease and repeated urinary infections, urinary tract obstruction by kidney stones, diabetic nephropathy, glomerulonephritis, and finally lupus erythematosus. High blood pressure, anemia, malnutrition, water retention, cardiovascular disease, and osteoporosis are common consequences that aggravate the state of chronic kidney disease patients. This high prevalence of behavioral and pathological factors, and the resulting consequences of CKD, suggest a major awareness of the Lebanese population of the risks of chronic kidney disease and the necessity of the prevention of CKD by following a healthy lifestyle and managing any existing diseases.

\section{Acknowledgments}

The authors wish to thank the patients and personnel of the hospitals for their cooperation

\section{Footnote}

Authors' Contribution: Ali Salami conceived the study idea, participated in the study design, coordinated the study, and was responsible for statistical analysis and drafting the manuscript. Fatima Karaki was responsible for collecting the data and evaluating the nutritional analysis of 
patients' dietary history. Wissam H. Joumaa participated in the study design and coordinated the study. All authors read and approved the final manuscript.

\section{References}

1. Costello-White R, Ryff CD, Coe CL. Aging and low-grade inflammation reduce renal function in middle-aged and older adults in Japan and the USA. Age (Dordr). 2015;37(4):9808. doi: 10.1007/s11357-015-9808-7. [PubMed: 26187318].

2. Weinstein JR, Anderson S. The aging kidney: physiological changes. Adv Chronic Kidney Dis. 2010;17(4):302-7. doi: 10.1053/j.ackd.2010.05.002. [PubMed: 20610357].

3. Malmgren L, McGuigan FE, Berglundh S, Westman K, Christensson A, Akesson K. Declining Estimated Glomerular Filtration Rate and Its Association with Mortality and Comorbidity Over 10 Years in Elderly Women. Nephron. 2015;130(4):245-55. doi: 10.1159/000435790. [PubMed: 26184510].

4. Couchoud C, Lassalle M, Stengel B, Jacquelinet C. Epidemiology and Information Network in nephrology. Néphrologie thérapeutique. 2009;5:3-144.

5. Adler AI, Stevens RJ, Manley SE, Bilous RW, Cull CA, Holman RR, et al. Development and progression of nephropathy in type 2 diabetes: the United Kingdom Prospective Diabetes Study (UKPDS 64). Kidney Int. 2003;63(1):225-32. doi: 10.1046/j.1523-1755.2003.00712.x. [PubMed: 12472787].

6. Hsiao CY, Lin HL, Lin YK, Chen CW, Cheng YC, Lee WC, et al. Urinary tract infection in patients with chronic kidney disease. TurkJ Med Sci. 2014;44(1):145-9. [PubMed: 25558575].

7. Gunay-Aygun M, Font-Montgomery E, Lukose L, Tuchman M, Graf J, Bryant JC, et al. Correlation of kidney function, volume and imaging findings, and PKHD1 mutations in 73 patients with autosomal recessive polycystic kidney disease. Clin J Am Soc Nephrol. 2010;5(6):972-84. doi: 10.2215/CJN.07141009. [PubMed: 20413436].

8. Rule AD, Bergstralh EJ, Melton L3, Li X, Weaver AL, Lieske JC. Kidney stones and the risk for chronic kidney disease. Clin J Am Soc Nephrol. 2009;4(4):804-11. doi: 10.2215/CJN.05811108. [PubMed: 19339425].

9. Jindal A, Whaley-Connell A, Sowers JR. Obesity and heart failure as a mediator of the cerebrorenal interaction. Contrib Nephrol. 2013;179:15-23. doi: 10.1159/000346718. [PubMed: 23652445].

10. Jain G, Jaimes EA. Nicotine signaling and progression of chronic kidney disease in smokers. Biochem Pharmacol. 2013;86(8):1215-23. doi: 10.1016/j.bcp.2013.07.014. [PubMed: 23892062].

11. Kabir MS, Dutta PK, Islam MN, Hasan MJ, Mondol G. Prevalence of risk factors of chronic kidney disease in adults. Mymensingh Med J. 2012;21(4):605-10. [PubMed: 23134905].

12. Najar MS, Saldanha CL, Banday KA. Approach to urinary tract infections. Indian J Nephrol. 2009;19(4):129.

13. Sumaili EK, Krzesinski JM, Zinga CV, Cohen EP, Delanaye P, Munyanga SM, et al. Prevalence of chronic kidney disease in Kinshasa: results of a pilot study from the Democratic Republic of Congo. Nephrol Dial Transplant. 2009;24(1):117-22. doi: 10.1093/ndt/gfn469. [PubMed: 18715963].

14. Xue C, Ye XD, Li W, Peng Q, Ding HY, Zhang YH, et al. Prevalence of chronic kidney disease in Jing adults in China: a village-based study. Clin Nephrol. 2013;79(1):50-6. doi: 10.5414/CN107511. [PubMed: 22948117].

15. Sule SD, Moodalbail DG, Burnham J, Fivush B, Furth SL. Predictors of kidney disease in a cohort of pediatric patients with lupus. Lupus. 2015;24(8):862-8. doi: 10.1177/0961203315570162. [PubMed: 25680740].

16. Stringer KD, Komers R, Osman SA, Oyama TT, Lindsley JN, Anderson S. Gender hormones and the progression of experimental polycystic kidney disease. Kidney Int. 2005;68(4):1729-39. doi: 10.1111/j.15231755.2005.00589.x. [PubMed: 16164649].
17. Salifu I, Tedla F, Pandey A, Ayoub I, Brown C, McFarlane SI, et al. Sleep duration and chronic kidney disease: analysis of the national health interview survey. Cardiorenal Med. 2014;4(3-4):210-6. doi: 10.1159/000368205. [PubMed: 25737685].

18. Lebov JF, Valladares E, Pena R, Pena EM, Sanoff SL, Cisneros EC, et al. A population-based study of prevalence and risk factors of chronic kidney disease in Leon, Nicaragua. Can J Kidney Health Dis. 2015;2:6. doi: 10.1186/s40697-015-0041-1. [PubMed: 25926994].

19. Sontrop JM, Dixon SN, Garg AX, Buendia-jimenez I, Dohein O, Huang SH, et al. Association between water intake, chronic kidney disease, and cardiovascular disease: a cross-sectional analysis of NHANES data. Am J Nephrol. 2013;37(5):434-42. doi: 10.1159/000350377. [PubMed: 23594828].

20. Strippoli GF, Craig JC, Rochtchina E, Flood VM, Wang JJ, Mitchell P. Fluid and nutrient intake and risk of chronic kidney disease. Nephrology (Carlton). 2011;16(3):326-34. doi: 10.1111/j.1440-1797.2010.01415.x. [PubMed: 21342326].

21. Fatehi-Hassanabad Z, Chan CB. Transcriptional regulation of lipid metabolism by fatty acids: a key determinant of pancreatic betacell function. Nutr Metab (Lond). 2005;2(1):1. doi: 10.1186/1743-7075-2-1. [PubMed: 15634355].

22. Boero R, Pignataro A, Quarello F. Salt intake and kidney disease. $J$ Nephrol. 2001;15(3):225-9.

23. Sharma S, McFann K, Chonchol M, de Boer IH, Kendrick J. Association between dietary sodium and potassium intake with chronic kidney disease in US adults: a cross-sectional study. Am J Nephrol. 2013;37(6):526-33. doi: 10.1159/000351178. [PubMed: 23689685].

24. Pinho NA, Silva GV, Pierin AM. Prevalence and factors associated with chronic kidney disease among hospitalized patients in a university hospital in the city of Sao Paulo, SP, Brazil. J Bras Nefrol. 2015;37(1):91-7. doi: 10.5935/0101-2800.20150013. [PubMed: 25923755].

25. Thomas R, Kanso A, Sedor JR. Chronic kidney disease and its complications. Prim Care. 2008;35(2):329-44. doi: 10.1016/j.pop.2008.01.008. [PubMed: 18486718] vii.

26. Goldenstein PT, Jamal SA, Moyses RM. Fractures in chronic kidney disease: pursuing the best screening and management. Curr Opin Nephrol Hypertens. 2015;24(4):317-23. doi: 10.1097/MNH.0000000000000131. [PubMed: 26050117].

27. Kammerer J, Ratican M, Mapes D. Anemia in CKD: prevalence, diagnosis, and treatment. Case study of the anemic patient. J Ame Nephrol Nurses' Assoc. 2002;29(4):371-4.

28. United States Renal Data $S$. Atlas of chronic kidney disease \& endstage renal disease in the United States. Philadelphia: Saunders; 2009.

29. Zelmanovitz T, Gerchman F, Balthazar AP, Thomazelli FC, Matos JD, Canani LH. Diabetic nephropathy. Diabetol Metab Syndr. 2009;1(1):10. doi: 10.1186/1758-5996-1-10. [PubMed: 19825147].

30. Chakkarwar VA. Smoking in diabetic nephropathy: sparks in the fuel tank?. World J Diabetes. 2012;3(12):186-95. doi: 10.4239/wjd.v3.112.186. [PubMed: 23301120].

31. Tofovic SP, Kost CJ, Jackson EK, Bastacky SI. Long-term caffeine consumption exacerbates renal failure in obese, diabetic, ZSF1 (fa-fa(cp)) rats. Kidney Int. 2002;61(4):1433-44. doi: 10.1046/j.15231755.2002.00278.x. [PubMed: 11918750].

32. Ritz E, Haxsen V. Diabetic nephropathy and anaemia. Eur J Clin Invest. 2005;35 Suppl 3:66-74. doi: 10.1111/j.1365-2362.2005.01544.x. [PubMed: 16281961].

33. Devins GM, Binik YM, Mandin H, Letourneau PK, Hollomby DJ, Barre PE, et al. The Kidney Disease Questionnaire: a test for measuring patient knowledge about end-stage renal disease. J Clin Epidemiol. 1990;43(3):297-307. [PubMed: 2313319].

34. Agrawal V, Barnes MA, Ghosh AK, McCullough PA. Questionnaire instrument to assess knowledge of chronic kidney disease clinical practice guidelines among internal medicine residents. J Eval Clin Pract. 2009;15(4):733-8. doi: 10.1111/j.1365-2753.2008.01090.x. [PubMed: 19674226]. 
35. Noubiap JJ, Naidoo J, Kengne AP. Diabetic nephropathy in Africa: A systematic review. World J Diabetes. 2015;6(5):759-73. doi: 10.4239/wjd.v6.i5.759. [PubMed: 26069725].

36. Maric-Bilkan C. Obesity and diabetic kidney disease. Med Clin North Am. 2013;97(1):59-74. doi: 10.1016/j.mcna.2012.10.010. [PubMed: 23290730].

37. Cameron JS, Simmonds HA. Hereditary hyperuricemia and renal disease. Seminars in nephrology. Elsevier; 2005. pp. 9-18.

38. Madala ND, Thusi GP, Assounga AG, Naicker S. Characteristics of South African patients presenting with kidney disease in rural KwaZuluNatal: a cross sectional study. BMCNephrol. 2014;15:61. doi:10.1186/14712369-15-61. [PubMed: 24731300].

39. Doumas M, Papademetriou V, Faselis C, Kokkinos P. Gender dif- ferences in hypertension: myths and reality. Curr Hypertens Rep. 2013;15(4):321-30. doi:10.1007/s11906-013-0359-y. [PubMed: 23749317].

40. Harrington RD, Hooton TM. Urinary tract infection risk factors and gender.J Gend Specif Med. 2000;3(8):27-34. [PubMed: 11253265].

41. Nasr SH, Markowitz GS, Stokes MB, Said SM, Valeri AM, D'Agati VD. Acute postinfectious glomerulonephritis in the modern era: experience with 86 adults and review of the literature. Medicine (Baltimore). 2008;87(1):21-32. doi: 10.1097/md.ob013e318161bofc. [PubMed: 18204367].

42. Mehdi U, Toto RD. Anemia, diabetes, and chronic kidney disease. Diabetes Care. 2009;32(7):1320-6. doi: 10.2337/dc08-0779. [PubMed: 19564475]. 